\title{
Communication
}

\section{The FMN "140s Loop" of Cytochrome P450 Reductase Controls Electron Transfer to Cytochrome P450}

\author{
Freeborn Rwere ${ }^{1,2, *}$, Sangchoul $\operatorname{Im}^{1,3}$ and Lucy Waskell ${ }^{1}$ \\ 1 Department of Anesthesiology, University of Michigan and VAMC, 2215 Fuller Road, Ann Arbor, MI 48105, \\ USA; scim@med.umich.edu (S.I.); waskell@umich.edu (L.W.) \\ 2 Department of Anesthesiology, Perioperative and Pain Medicine, Stanford University School of Medicine, \\ 300 Pasteur Drive, Stanford, CA 94305, USA \\ 3 Department of Internal Medicine, University of Michigan and VAMC, 2215 Fuller Road, \\ Ann Arbor, MI 48105, USA \\ * Correspondence: frwere@stanford.edu
}

Citation: Rwere, F.; Im, S.; Waskell, L. The FMN "140s Loop" of Cytochrome P450 Reductase Controls Electron Transfer to Cytochrome P450. Int. J. Mol. Sci. 2021, 22, 10625. https:// doi.org/10.3390/ijms221910625

Academic Editor: Patrick M. Dansette

Received: 31 August 2021

Accepted: 25 September 2021

Published: 30 September 2021

Publisher's Note: MDPI stays neutral with regard to jurisdictional claims in published maps and institutional affiliations.

Copyright: (c) 2021 by the authors. Licensee MDPI, Basel, Switzerland. This article is an open access article distributed under the terms and conditions of the Creative Commons Attribution (CC BY) license (https:// creativecommons.org/licenses/by/ $4.0 /)$.

\begin{abstract}
Cytochrome P450 reductase (CYPOR) provides electrons to all human microsomal cytochrome P450s (cyt P450s). The length and sequence of the "140s" FMN binding loop of CYPOR has been shown to be a key determinant of its redox potential and activity with cyt P450s. Shortening the "140s loop" by deleting glycine-141( $\Delta$ Gly141) and by engineering a second mutant that mimics flavocytochrome P450 BM3 ( $\Delta$ Gly141/Glu142Asn) resulted in mutants that formed an unstable anionic semiquinone. In an attempt to understand the molecular basis of the inability of these mutants to support activity with cyt P450, we expressed, purified, and determined their ability to reduce ferric P450. Our results showed that the $\Delta$ Gly141 mutant with a very mobile loop only reduced $\sim 7 \%$ of cyt P450 with a rate similar to that of the wild type. On the other hand, the more stable loop in the $\Delta$ Gly141/Glu142Asn mutant allowed for $\sim 55 \%$ of the cyt P450 to be reduced $\sim 60 \%$ faster than the wild type. Our results reveal that the poor activity of the $\Delta$ Gly141 mutant is primarily accounted for by its markedly diminished ability to reduce ferric cyt P450. In contrast, the poor activity of the $\Delta$ Gly141/Glu142Asn mutant is presumably a consequence of the altered structure and mobility of the "140s loop".
\end{abstract}

Keywords: cytochrome P450 reductase; cytochrome P450; cytochrome b5; redox potential; anionic semiquinone; hydroquinone; P450 BM3

\section{Introduction}

Cytochrome P450 reductase is a $\sim 78 \mathrm{kDa}$ diflavin oxidoreductase protein that delivers electrons to microsomal cytochromes P450, heme oxygenase, and cytochrome b5 [1-3]. Flavo-protein catalyzed reactions are versatile because of the presence of a unique flavin isoalloxazine ring system that can undergo redox linked chemical reactions [4,5]. Microsomal cytochromes P450, functioning as monooxygenases, catalyze the oxidative biotransformation of the majority of pharmaceuticals in current use, carcinogens and pro-carcinogens, fatty acids, and steroids [6-8]. CYPOR can provide the two electrons needed for the oxidation of different substrates, whereas cyt $b 5$ can only provide the second required electron [1,2]. The ability of CYPOR to donate electrons to P450s depends on the redox potential of its flavin cofactors, FMN and FAD. The redox potential of wild-type CYPOR for the $\mathrm{FMN}_{\mathrm{ox} / \mathrm{sq}}$ couple is found at $-56 \mathrm{mV}$, whereas the $\mathrm{FMN}_{\mathrm{sq}}$ /hq couple appears at $-252 \mathrm{mV}$ [9]. It is the low potential FMN hydroquinone that reduces microsomal cyts P450 heme. The structure and dynamics of the "140s" FMN loop of CYPOR (140-YGEGD-144) play a critical role in electron transfer to microsomal cyt P450s. In contrast, in the model bacterial cyt P450, BM3, where the heme-binding domain and flavin domain are fused in a single polypeptide chain, the redox potential of the oxidized/semiquinone $\mathrm{FMN}_{\mathrm{ox}} / \mathrm{sq}$ couple appears at $-240 \mathrm{mV}$, whereas the semiquinone/hydroquinone $\mathrm{FMN}_{\mathrm{sq}} / \mathrm{hq}$ couple 
is found at $-160 \mathrm{mV}$ [10]. It is the more-negative, low potential, unprotonated, anionic semiquinone $(-240 \mathrm{mV})$ that can reduce the P450 BM3 heme. The function of the "537s" loop (537-YNGH-540) of P450 BM3 is analogous to that of the "140s" loop of CYPOR. In this work, the CYPOR "140s" loop has been engineered (shortened by one amino acid and changed amino acid sequence) to resemble that of the "537s" FMN binding loop of P450 BM3 [9]. The engineered $\Delta$ Gly-141 mutants have redox properties similar to the flavo-cytochrome P450 BM3 but different from wild-type CYPOR. For example, the redox potentials of both $\Delta$ G141 and $\Delta$ G141/E142N mutants were reversed from those of wildtype CYPOR but similar to P450 BM3, that is the ox/sq mutant couple was lower, more negative, than the sq/hq couple. The $\Delta$ G141 redox potentials appeared at $-229 \mathrm{mV}$ for the $\mathrm{FMN}_{\mathrm{ox} / \mathrm{sq}}$ couple and $-53 \mathrm{mV}$ for the $\mathrm{FMN}_{\mathrm{sq} / \mathrm{hq}}$ couple, whereas those for $\Delta \mathrm{G} 141 / \mathrm{E} 142 \mathrm{~N}$ were found at $-281 \mathrm{mV}\left(\mathrm{FMN}_{\mathrm{ox} / \mathrm{sq}}\right)$ and $-204 \mathrm{mV}\left(\mathrm{FMN}_{\mathrm{sq} / \mathrm{hq}}\right)$ [9].

The redox potential of substrate-bound, ferric cyt P450 2B4 is approximately $-245 \mathrm{mV}$ [11]. Based on its redox potential $(-281 \mathrm{mV})$ for $\mathrm{FMN}_{\mathrm{ox} / \mathrm{sq}}$, the anionic semiquinone of the $\Delta \mathrm{G} 141 / \mathrm{E} 142 \mathrm{~N}$ is thermodynamically competent to transfer electrons to substrate-bound ferric cyt P450 2B4. The $\Delta$ G141 mutant with a redox potential of $-229 \mathrm{mV}$ for $\mathrm{FMN}_{\mathrm{ox} / \mathrm{sq}}$ should at least partially reduce ferric P450. Cyt $b 5(\sim 25 \mathrm{mV})$ cannot reduce ferric cytochrome $\mathrm{P} 450$ but can transfer the second electron to the high potential oxy-ferrous cytochrome P450 [12]. To better understand the molecular basis of the previously reported mutants' low activity with cyt P450, we asked whether the mutants could reduce ferric cyt P450 and whether cyt $b 5$ would be able to restore the activity of $\Delta \mathrm{G} 141$ and $\Delta$ G141/E142N mutants by reducing oxyferrous cyt P450. In other words, can activity be increased by having the anionic semiquinone of $\Delta \mathrm{G} 141$ or $\Delta \mathrm{G} 141 / \mathrm{E} 142 \mathrm{~N}$ mutant transfer the first electron to cyt $\mathrm{P} 4502 \mathrm{~B} 4$, and then can cyt $b 5$ provide the second electron and restore the activity of the mutant reductases?

\section{Results}

2.1. Comparison of the Kinetics of Reduction of Ferric Cytochrome P450 by Wild Type and Mutant Reductases

The location of Gly141 and G143 residues in the "140s loop" of oxidized wild-type rat cytochrome P450 reductase is shown in Figure 1A. In its oxidized form, the "140s loop" of CYPOR forms a Gly141-Glu142 peptide bond adopting an O-down conformation, which rotates to an up position in the reduced protein (Figure 1B). In the wild type reduced CYPOR, the backbone carbonyl oxygen of Gly141 hydrogen bonds to the hydrogen on nitrogen 5 (N5) in the reduced flavin, thereby stabilizing the uncharged-neutral, blue semiquinone (Figure 1B). Upon Gly141 deletion ( $\Delta$ G141), the amide nitrogen of Glu 142 in the shortened "140s loop" is so close to the FMN N5 atom that it sterically hinders the flavin N5 protonation. As a result of the unfavorable protonation of N5, the one-electron reduced flavin forms a negatively-charged anionic semiquinone that leads to a decrease in its potential. Furthermore, the reduced form of $\Delta$ G141 cannot (unlike the reduced wild type) undergo a peptide bond flip that creates the stabilizing interaction between the flavin $\mathrm{N} 5$ and backbone $\mathrm{C}=\mathrm{O}$, carbonyl. The main chain amide nitrogens of Glu142 and Gly143 make two H-bonds with nitrogen 5, N5, and oxygen, O4, of the FMN ring, respectively (Figure 1C). When Gly141 is deleted and Glu142 mutated to Asn142 ( $\triangle$ G141/E142N) in order to mimic the sequence of the P450 BM3 FMN loop, the backbone amide nitrogen of Asn142 and Gly143 form H-bonds with the unprotonated N5 and O4 of the FMN ring. These H-bonds decrease the mobility of the mutants' loop (Figure 1D). Recall that, in the wild type, the flavin N5 becomes protonated upon reduction and the G141 backbone oxygen flips up toward the flavin and H-bonds with hydrogen on N5 while the amide nitrogen of G143 still H-bonds with the flavin O4. The shortening of the loop in the G141 deletion mutants, which brings the residues in the loop closer to the flavin, allows the amide of the amino acid (glutamic acid or asparagine) following the missing glycine to $\mathrm{H}$-bond with the unprotonated N5 in the oxidized flavin and sterically prevent protonation upon reduction. In the shortened, very mobile loop of the $\Delta \mathrm{G} 143$ structure, no H-bonds between the flavin and the loop are observed. However, the properties and activity of 
the $\Delta \mathrm{G} 143$ indicate that $\mathrm{H}$-bonds similar to those in the wild type are formed transiently (Figure 1E).
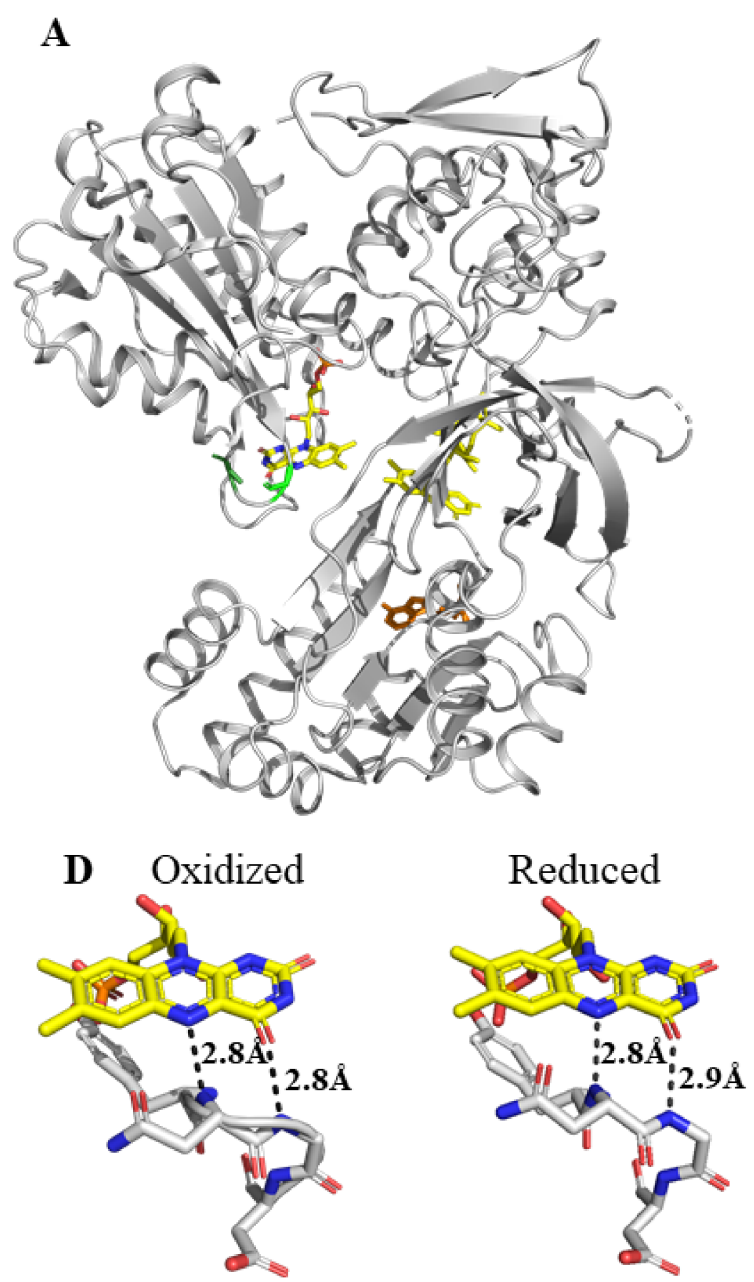
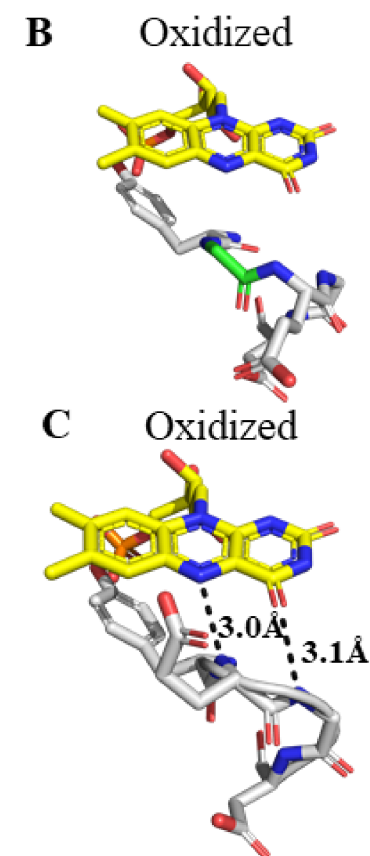

E Oxidized

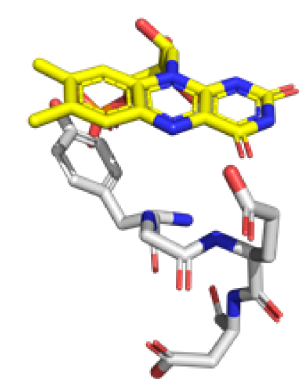

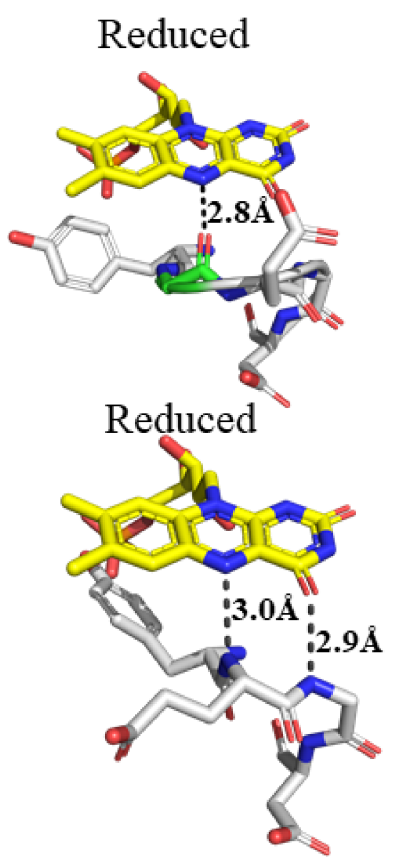

Reduced

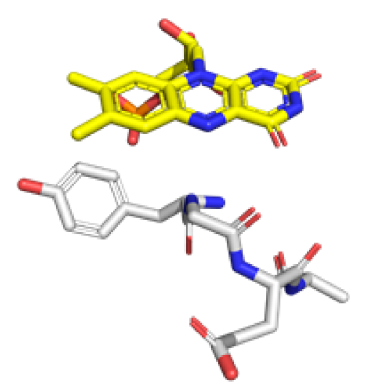

Figure 1. Comparison of the structure of the "140s loop" in the wild-type CYPOR and $\Delta$ G141, $\Delta$ G141/E142N and $\Delta$ G143 mutants. The 140s loop controls the FMN redox potential and electron transfer to P450s. (A) Structure of the oxidized wild-type CYPOR (PDB ID: 4YAF), with two amino acids within the structure highlighted, Gly141 (light green) and Gly143 (dark green). (B) Wild-type oxidized (ox) (PDB ID: 4YAF) and reduced (red) (PDB ID: 4YAL) 140s loop. Upon reduction, the loop flips up toward the flavin and forms a stable hydrogen bond (H-bond) between the protonated flavin nitrogen 5 ( $\mathrm{N} 5 \mathrm{H}$ ) and the Gly141 carbonyl oxygen. (C) The shorter $\Delta$ G141 oxidized (PDB ID: 4Y9R) and reduced (PDB ID: 4YAW) loop, which is closer to the flavin than in the wild-type protein, sterically hinders N5 protonation and forms $2 \mathrm{H}$-bonds between amide nitrogens of Glu142 and Gly143 and the N5 and O4 of the FMN ring, respectively. (D) The shorter $\Delta$ G141/E142N oxidized (PDB ID: 4Y7C) and reduced (PDB ID: 4YAU) loops form two relatively strong H-bonds between the amide nitrogens of Asn142 and Gly143 with N5 and O4 of the FMN ring, respectively. (E) The $\Delta$ G143 oxidized (PDB ID: 4Y9U) and reduced (PDB ID: 4YAO) loop is highly disordered and mobile with a higher average B-factor than the average B-factor of the whole CYPOR.

In an attempt to determine whether the anionic semiquinone of the $\Delta \mathrm{Gly}-141$ reductase mutants can reduce ferric cyt P450 2B4, we investigated the rate of first electron transfer to ferric cyt P450. By monitoring the absorbance increase at $450 \mathrm{~nm}$ as a result of formation of a ferrous cyt $\mathrm{P} 450-\mathrm{CO}$ adduct, we can determine whether the mutants deliver electrons to P450s [13]. Figure 2 and Table 1 show the rate and extent of reduction of ferric cyt P450 2B4 by wild-type CYPOR and the glycine deletion mutants under conditions similar to those employed to measure activity. The reduction of cyt P450 2B4 (-245 mV) by the FMN hydroquinone $(-252 \mathrm{mV})$ of wild-type CYPOR when monitored at $450 \mathrm{~nm}$ is biphasic with 
the biphasic rate constants $\mathrm{k}_{1}=9.93 \mathrm{~s}^{-1}$ and $\mathrm{k}_{2}=0.54 \mathrm{~s}^{-1}$. The fast phase $\left(\mathrm{k}_{1}=9.93 \mathrm{~s}^{-1}\right)$ represents the transfer of electrons from the FMN hydroquinone to approximately $80 \%$ of the ferric cyt P450 [13]. In the fast phase of the biphasic reduction of ferric cyt P450 2B4 by the $\Delta \mathrm{G} 143$ mutant $\left(\mathrm{k}_{1}=3.34 \mathrm{~s}^{-1}\right.$ and $\left.\mathrm{k}_{2}=0.11 \mathrm{~s}^{-1}\right)$, approximately $60 \%$ of the ferric P450 is reduced approximately $66 \%$ slower than those of wild-type CYPOR (Tables 1 and 2). In contrast, the reduction of ferric cyt P450 2B4 by the $\Delta$ G141/E142N mutant produced two distinct phases, a fast phase $\left(\mathrm{k}_{1}=16.29 \mathrm{~s}^{-1}\right)$ and a very slow phase $\left(\mathrm{k}_{2}=0.03 \mathrm{~s}^{-1}\right)$. The fast phase $\left(\mathrm{k}_{1}=16.29 \mathrm{~s}^{-1}\right)$ represents electron transfer from the moderately stable, low-potential anionic FMN semiquinone to ferric cyt P450. Since the anionic semiquinone is short lived at $\mathrm{pH} 7.4\left(\mathrm{t}_{1 / 2}<0.1 \mathrm{~s}\right)$, it was only able to reduce $\sim 55 \%$ of the ferric cyt $\mathrm{P} 450$ 2B4 [9]. The source of the electrons for the slower phase of reduction is not understood at this time. The reduction of ferric cytP450 2B4 by the $\Delta \mathrm{G} 141$ mutant was fitted to a triphasic exponential function with a small fast phase $\left(\mathrm{k}_{1}=9.12 \mathrm{~s}^{-1}\right)$ and two larger amplitude slow phases $\left(k_{1}=0.03 \mathrm{~s}^{-1}\right.$ and $\left.\mathrm{k}_{2}=0.01 \mathrm{~s}^{-1}\right)$ (Table 1, Figure 2 and Figure S1). The fast phase $\left(\mathrm{k}_{1}=9.12 \mathrm{~s}^{-1}\right)$ with a small amplitude $(\sim 7 \%)$ presumably represents electron transfer from the transient anionic semiquinone to $7 \%$ of ferric cyt P450 2B4.



Figure 2. Kinetics of the reduction of ferric cyt P450 2B4 by WT CPR, $\Delta \mathrm{G} 141, \Delta \mathrm{G} 141 / \mathrm{E} 142 \mathrm{~N}$ and $\Delta \mathrm{G} 143$ in the presence of 10 -fold excess of NADPH monitored at $450 \mathrm{~nm}$. The experiment was conducted under anaerobic conditions at $\mathrm{pH} 7.4$ and $30{ }^{\circ} \mathrm{C}$.

Table 1. Kinetics of the reduction of substrate-bound ferric cyt P450 2B4 by WT CYPOR and G141 loop mutants in the presence of a 10-fold excess of NADPH at $\mathrm{pH} 7.4$.

\begin{tabular}{|c|c|c|c|c|}
\hline \multicolumn{5}{|c|}{$\lambda=450 \mathrm{~nm}$} \\
\hline Enzyme & $\begin{array}{c}\mathrm{k}_{1 \mathrm{obs}}\left(\mathrm{s}^{-1}\right) \\
\text { (amplitude\%) }\end{array}$ & $\begin{array}{c}\mathbf{k}_{\text {2obs }}\left(\mathrm{s}^{-1}\right) \\
\text { (amplitude\%) }\end{array}$ & $\begin{array}{c}\mathrm{k}_{3 o b s}\left(\mathrm{~s}^{-1}\right) \\
\text { (amplitude\%) }\end{array}$ & $\mathbf{R}^{2}$ \\
\hline WT CPR & $9.93 \pm 0.17(82.8 \pm 0.2)$ & $0.54 \pm 0.014(17.2 \pm 0.2)$ & & 0.9951 \\
\hline$\Delta \mathrm{G} 141$ & $9.12 \pm 0.10(7.2 \pm 0.3)$ & $0.03 \pm 0.001(89.2 \pm 0.6)$ & $0.01 \pm 0.001(3.6 \pm 0.2)$ & 0.9994 \\
\hline$\Delta \mathrm{G} 141 / \mathrm{E} 142 \mathrm{~N}$ & $16.29 \pm 0.31(60.1 \pm 0.8)$ & $0.03 \pm 0.001(39.9 \pm 0.8)$ & & 0.9938 \\
\hline$\Delta \mathrm{G} 143$ & $3.34 \pm 0.10(81.8 \pm 0.1)$ & $0.11 \pm 0.01(18.2 \pm 0.1)$ & & 0.9943 \\
\hline
\end{tabular}


Table 2. Effect of cyt $b 5$ on the rate of benzphetamine metabolism by cyt P450 2B4 under steady-state conditions, as described in the "Materials and Methods" section.

\begin{tabular}{ccc}
\hline $\begin{array}{c}\text { Full-Length CYPOR } \\
\text { Reductase } \\
\text { Mutant/Wild-Type }\end{array}$ & $\begin{array}{c}\text { Molar Ratio } \\
\text { P450:CYPOR:Cyt } \mathbf{b 5}\end{array}$ & $\begin{array}{c}\text { Benzphetamine Nmol of } \\
\mathbf{C H}_{\mathbf{2}} \text { O Produced/s/nmol } \\
\text { CYPOR }\end{array}$ \\
\hline WT & $1: 1: 0$ & $0.68 \pm 0.01$ \\
& $1: 1: 0.5$ & $0.82 \pm 0.04$ \\
& $1: 1: 1$ & $0.73 \pm 0.04$ \\
& $1: 1: 1.5$ & $0.63 \pm 0.01$ \\
& $1: 1: 2$ & $0.52 \pm 0.01$ \\
& $1: 1: 5$ & $0.26 \pm 0.02$ \\
& $1: 1: 0$ & $0.004 \pm 0.001$ \\
& $1: 1: 0.5$ & $0.01 \pm 0.003$ \\
& $1: 1: 1$ & No activity \\
& $1: 1: 1.5$ & No activity \\
& $1: 1: 2$ & No activity \\
& & \\
& $1: 1: 0$ & $0.001 \pm 0.0006$ \\
& $1: 1: 0.5$ & $0.01 \pm 0.003$ \\
& $1: 1: 1$ & No activity \\
& $1: 1: 1.5$ & No activity \\
& $1: 1: 2$ & No activity \\
& & \\
& $1: 1: 0$ & $0.08 \pm 0.005$ \\
& $1: 1: 0.5$ & $0.11 \pm 0.003$ \\
& $1: 1: 1$ & $0.07 \pm 0.011$ \\
& $1: 1: 2$ & $0.05 \pm 0.002$ \\
& & $0.03 \pm 0.001$ \\
\hline
\end{tabular}

2.2. Effect of Cytochrome b5 on the Rate of Benzphetamine Metabolism by Cyt P450 2B4 under Steady-State Conditions at $30^{\circ} \mathrm{C}$ in the Presence of Wild-Type and Mutant Reductases

In an effort to understand the biochemical basis of the inability of the glycine deletion mutants to support cyt P450 catalysis, we asked whether cyt $b 5$ could increase the activity of the Gly141 mutants by providing the second electron to oxyferrous P450 after the mutants provided the first electron to ferric cyt P450. As shown in Table 2, the activity of wild-type CYPOR was modestly enhanced at a low concentration of cyt $b 5(0.68 \mathrm{vs} .0 .82 \mathrm{nmol} / \mathrm{s} / \mathrm{nmol}$ of CYPOR). The maximum increase in activity of wild-type CYPOR was achieved at molar ratios of 1:0.5 for CYPOR and cyt $b 5$, respectively. At high concentrations of cyt $b 5$, the activity of P450 2B4 was greatly reduced because cyt $b 5$ occupies the CYPOR binding site on the proximal surface of P450 2B4 and prevents a reduction of ferric P450 (Table 2) [12]. Since cyt $b 5$ can enhance the activity of reductases at low concentrations, the glycine deletion mutants were also examined for their ability to support metabolism of benzphetamine in the presence of various concentrations of cyt $b 5$ in order to investigate whether cyt $b 5$ can augment the activity of these mutant reductases. As shown in Table 2, the $\Delta \mathrm{G} 141$ and $\Delta$ G141/E142N mutants are essentially inactive in the absence of cyt $b 5$. Addition of cyt $b 5$ at various concentrations did not significantly enhance the activity. The activity of $\Delta$ Gly 143 mutant was slightly enhanced at a lower molar ratio of cyt $b 5(0.08 \mathrm{vs} .0 .11 \mathrm{nmol} / \mathrm{s} / \mathrm{nmol}$ of $\Delta \mathrm{G} 143 \mathrm{CYPOR})$. However, at higher cyt $b 5$ concentrations, the activity of $\Delta \mathrm{G} 143$ is reduced significantly.

\section{Discussion}

Structural differences between CYPOR/P450 2B4 and flavo-cytochrome P450 BM3 from the Bacillus megaterium system account for their differences in redox potentials and reactivity. In this work, we deleted a conserved Gly141 and mutated Glu142 to asparagine in order to mimic the P450 BM3 FMN binding loop. We also deleted glycine 143 in order to 
test whether a shortened and less flexible "140s" loop can reduce ferric P450 2B4. Our results showed that $\triangle \mathrm{G} 141$ can transfer the first electron to ferric CYP2B4 at a rate approximately equal to the wild type, whereas $\Delta$ G141/E142N reduces ferric CYP2B4 at a rate $\sim 1.6$-fold higher than the wild type, consistent with its more negative potential, thermodynamically favorable anionic semiquinone. The amount of heme reduced by anionic semiquinone was significantly different between $\Delta$ Gly141 and $\Delta$ G141/E142N ( $7 \%$ for $\Delta$ G141 vs. $55 \%$ for $\Delta$ G141/E142N). Both $\Delta$ Gly141 and $\Delta$ G141/E142N mutants were inactive with CYP2B4, and their activities were not significantly stimulated by cytochrome $b 5$. The increase in rate of heme reduction and greater amount of heme reduced by $\Delta$ G141/E142N vs. $\Delta$ G141 can be attributed to a more rigid "140s" FMN loop and a greater thermodynamic driving force, i.e., a lower potential.

A closer look at the crystal structures of the reduced $\Delta$ Gly-141 mutants reveals that $\Delta$ G141 and $\Delta$ G141/E142N form two H-bonds between E142 or N142 and G143 with N5 and $\mathrm{O} 4$ of the FMN (Figure 1C,D). The mobility of their "140s" loop is considered different. The crystal structure suggests that, in some conformations the 5 carbon long glutamic acid can sterically collide with the flavin ring, which prevents stable intramolecular interactions. In contrast, a shorter four-carbon asparagine side chain at position 142 does not collide with the flavin and consequently forms more stable interactions in the molecule. The more stable loop and low potential anionic semiquinone in the $\Delta \mathrm{G} 141 / \mathrm{E} 142 \mathrm{~N}$ structure versus a dynamic loop and higher potential anionic semiquinone in the $\Delta$ G141 structure allows ferric P450 to be significantly and quickly reduced versus $\Delta$ G141 where the higher potential anionic semiquinone quickly decays to the hydroquinone with a potential of $\sim-53 \mathrm{mV}$, which cannot reduce ferric cyt P450. It should also be noted that the hydroquinone is more negative in the E142N protein again a reflection of a stable loop. Another difference between the $\Delta \mathrm{G} 141 / \mathrm{E} 142 \mathrm{~N}$ and the analogous FMN domain loop of flavo-cytochrome $\mathrm{P} 450 \mathrm{BM} 3$ is that the P450 BM3 loop ends with two rigid proline residues that essentially immobilize the loop. In this conformation, the amide proton of Asn-537 in P450 BM3 forms a strong H-bond with $\mathrm{N} 5$ atom of the FMN isoalloxazine ring, while Thr577 forms another H-bond with a keto O4 of FMN. This more stable and less dynamic FMN P450 BM3 loop allows the anionic semiquinone to reduce the heme at significantly higher rates compared with the engineered $\Delta$ Gly-141 mutants. Flavo-cytochrome P450 BM3 oxidizes substrates at high turnover rates of $>1000 / \mathrm{min}$ [14]. A comparison of the structure of the flavo-cytochrome P450 BM3 system with the CYPOR/cyt P450 2B4 system reveals that the lack of enzymatic activity of the $\Delta$ G141/E142N mutant is due to the decreased stability of anionic semiquinone and the relatively longer time required for the mutant CYPOR to bind to cyt P450. In the two-separate-protein CYPOR/cyt P450 2B4 system, the two proteins must come into contact prior to heme reduction; in contrast, in the P450 BM3 system, the reductase and cyt $\mathrm{P} 450$ are fused in a single polypeptide chain.

The $\Delta$ G143 mutant reduced substrate-bound ferric cyt P450 2B4 at a significantly slower rate compared with wild-type CYPOR. The amount of heme reduced by this mutant was comparable with wild-type CYPOR. However, as shown in Table 2, the activity of $\Delta$ G143 is significantly lower than that of the wild type and is slightly enhanced by cytochrome $b 5$. The markedly reduced activity of the $\Delta \mathrm{G} 143$ mutant with cyt P450 2B4 under steady-state conditions (Table 2) is likely due to slower rate of reduction and the presence of a flexible FMN "140s loop", which prevents tight docking with cyt P450 2B4. The interaction between the mutant reductases, and ferric and oxyferrous P450 may be different, with the oxyferrous protein having more stringent structural requirements for reduction and catalysis. It has been reported that P450 camphor has more specific requirements for reduction of the oxyferrous compared to the ferric protein, and this may also be the case with P4502B4 [15]. The biochemical basis for the slight stimulation of the $\Delta$ G143 mutant at lower concentrations of cyt $b 5$ is likely due to its ability to increase the rate of proton delivery to the hydroperoxo $\left(\mathrm{Fe}^{3+} \mathrm{OOH}\right)^{-}$intermediate and thereby to enhance formation of the oxyferryl $\left(\mathrm{Fe}^{4+} \mathrm{O}\right) \pi$ cation radical, Compound $\mathrm{I}$, and to decrease side product $\left(\mathrm{H}_{2} \mathrm{O}_{2}\right)$ formation [16]. The inhibitory effects of cytochrome $b 5$ on activity of 
$\Delta \mathrm{G} 143$ at higher concentrations are presumably due to competition between the reductases and cyt $b 5$ for the binding site on the proximal surface of P450 2B4 [12].

In summary, the results presented here demonstrate for the first time that an anionic semiquinone of the $\Delta$ G141/E142N mutant can transfer the first electron to substrate-bound ferric cyt P450 2B4 at an initial rate 1.6 times faster than that of the FMN hydroquinone of wild-type CYPOR. This may be due to a $\sim 50 \mathrm{mV}$ greater thermodynamic driving force ( $\Delta$ G141/E142 $-281 \mathrm{mV}$ ox/sq vs. wild type $-252 \mathrm{mV}$ sq/hq). The more transient anionic semiquinone of $\Delta \mathrm{G} 141$ mutant also reduced $\sim 7 \%$ of ferric cytochrome P450 2B4, slightly slower than the wild-type reductase. Our results also indicate that the length and dynamics of the FMN loop of CYPOR are major determinants of electron transfer to microsomal P450s. Finally, the activity of the $\Delta \mathrm{Gly}-141$ mutants with cyt P450 was not enhanced by the presence of cytochrome $b 5$.

\section{Materials and Methods}

\subsection{Construction of Site-Directed Mutants of the Full-Length CYPOR}

Construction of site-directed mutants of the full-length rat CYPOR $(\Delta \mathrm{G} 141, \Delta \mathrm{G} 141$ / E142N and $\Delta$ G143) were according to guidelines from the QuikChange II XL site directed mutagenesis kit (Agilent Technologies) as previously described [9]. The oligomers for site-directed mutagenesis are presented in Table 3. The mutated DNA was sequenced at the University of Michigan DNA Sequencing Core Facility.

Table 3. Sequences of oligonucleotide primers used to mutate full length rat cyt P450 reductase (CYPOR).

\begin{tabular}{cc}
\hline Mutant & Sequence \\
\hline$\Delta$ G141 (Forward) & $5^{\prime}$-TGC ATG GCC ACA TAC - GAG GGC GAC C-3' \\
$\Delta$ G141/E142N (Forward) & $5^{\prime}$-TGC ATG GCC ACA TAC - AAC GGC GAC C-3' \\
$\Delta$ G143 (Forward) & $5^{\prime}$-ATG GCC ACA TAC GGA GAG - GAC CCC A-3' \\
\hline
\end{tabular}

\subsection{Expression and Purification of the Full-Length Wild-Type (WT) and Glycine Deletion CYPOR} Mutants

The expression of full-length wild-type and mutant CYPOR was conducted according to the published procedures $[9,17]$ in the presence of $0.24 \mathrm{mM}$ carbenicillin, $0.2 \%(\mathrm{w} / \mathrm{v})$ glucose and $5.3 \mathrm{nM}$ riboflavin. For induction, $0.4 \mathrm{mM}$ IPTG (isopropylthio- $\beta$-galactoside) was used. The full-length wild-type CYPOR and glycine deletion mutants were purified as previously described $[9,17]$. A $10 \%$ SDS gel was run on purified proteins, and they all gave a single band at $\sim 74 \mathrm{kDa}$. The average yield of pure full-length wild-type and mutant reductase proteins was $\sim 20-25 \mathrm{mg} / \mathrm{L}$.

\subsection{Measurement of Benzphetamine Metabolism by Cyt P450 2B4}

Wild-type rabbit cyt $\mathrm{P} 4502 \mathrm{~B} 4$ and rabbit cyt $b 5$ were expressed and purified as previously described $[12,13,18]$. The metabolism of benzphetamine was carried out at $30^{\circ} \mathrm{C}$ under steady-state conditions by mixing various concentrations of microsomal cyt $b 5(0,0.1,0.2,0.3$ and $0.4 \mu \mathrm{M})$ and a fixed concentration of cyt P450 $2 \mathrm{~B} 4(0.2 \mu \mathrm{M})$ and CYPOR $(0.2 \mu \mathrm{M})$ in the presence of DLPC $(225 \mu \mathrm{M})$, and incubating the mixture for $1 \mathrm{~h}$ at room temperature. The solution was then diluted to $0.8 \mathrm{~mL}$ with $50 \mathrm{mM}$ potassium phosphate buffer, $\mathrm{pH} 7.4$, containing $1 \mathrm{mM}$ benzphetamine. The resultant mixture was equilibrated for $5 \mathrm{~min}$ at $30^{\circ} \mathrm{C}$, and the reaction was initiated by adding NADPH $(300 \mu \mathrm{M}$ final concentration). The reaction was allowed to proceed for $6 \mathrm{~min}$ at $30^{\circ} \mathrm{C}$. After $6 \mathrm{~min}$, the reaction was quenched immediately with $70 \%$ trichloroacetic acid. The quenched reaction mixtures were centrifuged at 13,000 x g for $5 \mathrm{~min}$, and $200 \mathrm{~mL}$ of supernatant was assayed for formaldehyde using Nash's reagent according to the published protocols and the amount of formaldehyde formed from metabolism of benzphetamine by cyt P450 2B4 was calculated from the calibration curve. [13,18-20]. The values in Table 2 are an average of three measurements on two separate days. 


\title{
4.4. Kinetics of the Reduction of Ferric Cyt P450 2B4 by CYPOR
}

The rate of electron transfer from wild-type or mutant CYPOR to ferric cyt P450 $2 \mathrm{~B} 4$ was measured at $30^{\circ} \mathrm{C}$ with stopped-flow spectrophotometry by monitoring the absorbance increase at $450 \mathrm{~nm}$ as a result of formation of the ferrous cyt P450-CO adduct. The stopped-flow experiments were performed using a Hi-Tech SF61DX2 stopped-flow spectrophotometer (Hi-Tech, Wiltshire, UK) housed in an anaerobic chamber (Belle Technology, Dorset, UK) as reported previously [13]. A solution containing $5 \mu \mathrm{M} \mathrm{P} 4502 \mathrm{~B} 4$ and $5 \mu \mathrm{M}$ CYPOR in $0.1 \mathrm{M}$ potassium phosphate, $\mathrm{pH} 7.4,15 \%$ glycerol, $300 \mu \mathrm{M}$ DLPC, and $1 \mathrm{mM}$ benzphetamine was prepared under anaerobic conditions. The anaerobic protein mixture was rapidly mixed with a carbon monoxide saturated $0.1 \mathrm{M}$ potassium phosphate buffer, $\mathrm{pH} 7.4$, containing $15 \%$ glycerol, $1 \mathrm{mM}$ benzphetamine, and $50 \mu \mathrm{M} \mathrm{NADPH}$ at $25^{\circ} \mathrm{C}$. The absorbance change at $450 \mathrm{~nm}$ was recorded as a function of time. The rate constants and amplitudes were obtained by fitting the absorbance change at $450 \mathrm{~nm}$ with a double exponential function (nonlinear curve fit) for wild-type, $\Delta \mathrm{G} 141 / \mathrm{E} 142 \mathrm{~N}$ and $\Delta \mathrm{G} 143 \mathrm{using}$ KinetAsyst2 software (Hi-Tech) and GraphPad Prism. A triple exponential function was used for $\Delta$ G141 mutant, and the kinetic parameters are shown in Table 1.

Supplementary Materials: Supplementary materials can be found at https:/ /www.mdpi.com/ article/10.3390/ijms221910625/s1.

Author Contributions: The manuscript was written through contributions of all authors. All authors have read and agreed to the published version of the manuscript.

Funding: This work was supported in whole or in part by the National Institute of Health grants GM035533 and GM094209 to LW, who also received funding from VA Merit review grant Project ID 1168720, and a Stanford University Education Department Fund (EDF) to FR.

Institutional Review Board Statement: Not applicable.

Informed Consent Statement: Not applicable.

Data Availability Statement: Not applicable.

Acknowledgments: The authors acknowledge Eric R. Gross, Department of Anesthesiology, Perioperative and Pain Medicine, Stanford School of Medicine for reading the manuscript and for providing valuable guidance in its preparation.

Conflicts of Interest: The authors declare no competing financial interests.

\author{
Abbreviations \\ Cytochrome P450 reductase, CYPOR; wild type, WT; cytochrome b5, cyt b5; cytochrome P450, P450 \\ or cyt P450; flavo-cytochrome P450 BM3, P450 BM3; oxidized, ox; reduced, red; semiquinone, sq; \\ hydroquinone, hq.
}

\section{References}

1. Iyanagi, T.; Xia, C.; Kim, J.-J.P. NADPH-cytochrome P450 oxidoreductase: Prototypic member of the diflavin reductase family. Arch. Biochem. Biophys. 2012, 528, 72-89. [CrossRef] [PubMed]

2. Waskell, L.; Kim, J.-J.P. Electron Transfer Partners of Cytochrome P450. In Cytochrome P450; Springer International Publishing: Cham, Switzerland, 2015; pp. 33-68.

3. Iyanagi, T. Molecular mechanism of metabolic NAD(P)H-dependent electron-transfer systems: The role of redox cofactors. Biochim. Biophys. Acta-Bioenerg. 2019, 1860, 233-258. [CrossRef] [PubMed]

4. Miura, R. Versatility and specificity in flavoenzymes: Control mechanisms of flavin reactivity. Chem. Rec. 2001, 1, 183-194. [CrossRef] [PubMed]

5. Li, H.; Das, A.; Sibhatu, H.; Jamal, J.; Sligar, S.G.; Poulos, T.L. Exploring the electron transfer properties of neuronal nitric-oxide synthase by reversal of the FMN redox potential. J. Biol. Chem. 2008, 283, 34762-34772. [CrossRef] [PubMed]

6. Guengerich, F.P. Human Cytochrome P450 Enzymes. In Cytochrome P450; Springer International Publishing: Cham, Switzerland, 2015; pp. 523-785.

7. Ortiz de Montellano, P.R. Hydrocarbon Hydroxylation by Cytochrome P450 Enzymes. Chem. Rev. 2010, 110, 932-948. [CrossRef] [PubMed] 
8. Šrejber, M.; Navrátilová, V.; Paloncýová, M.; Bazgier, V.; Berka, K.; Anzenbacher, P.; Otyepka, M. Membrane-attached mammalian cytochromes P450: An overview of the membrane's effects on structure, drug binding, and interactions with redox partners. J. Inorg. Biochem. 2018, 183, 117-136. [CrossRef] [PubMed]

9. Rwere, F.; Xia, C.; Im, S.; Haque, M.M.; Stuehr, D.J.; Waskell, L.; Kim, J.-J.P. Mutants of Cytochrome P450 Reductase Lacking Either Gly-141 or Gly-143 Destabilize Its FMN Semiquinone. J. Biol. Chem. 2016, 291, 14639-14661. [CrossRef] [PubMed]

10. Hanley, S.C.; Ost, T.W.B.; Daff, S. The unusual redox properties of flavocytochrome P450 BM3 flavodoxin domain. Biochem. Biophys. Res. Commun. 2004, 325, 1418-1423. [CrossRef]

11. Zhang, H.; Gruenke, L.; Arscott, D.; Shen, A.; Kasper, C.; Harris, D.L.; Glavanovich, M.; Johnson, R.; Waskell, L. Determination of the Rate of Reduction of Oxyferrous Cytochrome P450 2B4 by 5-Deazariboflavin Adenine Dinucleotide T491V Cytochrome P450 Reductase t. Biochemistry 2003, 42, 11594-11603. [CrossRef]

12. Zhang, H.; Im, S.-C.; Waskell, L. Cytochrome b5 Increases the Rate of Product Formation by Cytochrome P450 2B4 and Competes with Cytochrome P450 Reductase for a Binding Site on Cytochrome P450 2B4. J. Biol. Chem. 2007, 282, 29766-29776. [CrossRef] [PubMed]

13. Zhang, H.; Hamdane, D.; Im, S.-C.; Waskell, L. Cytochrome b5 Inhibits Electron Transfer from NADPH-Cytochrome P450 Reductase to Ferric Cytochrome P450 2B4. J. Biol. Chem. 2008, 283, 5217-5225. [CrossRef] [PubMed]

14. NOBLE, M.A.; MILES, C.S.; CHAPMAN, S.K.; LYSEK, D.A.; MACKAY, A.C.; REID, G.A.; HANZLIK, R.P.; MUNRO, A.W. Roles of key active-site residues in flavocytochrome P450 BM3. Biochem. J. 1999, 339, 371-379. [CrossRef] [PubMed]

15. Tripathi, S.; Li, H.; Poulos, T.L. Structural basis for effector control and redox partner recognition in cytochrome P450. Science 2013, 340, 1227-1230. [CrossRef] [PubMed]

16. Pearl, N.M.; Wilcoxen, J.; Im, S.; Kunz, R.; Darty, J.; Britt, R.D.; Ragsdale, S.W.; Waskell, L. Protonation of the Hydroperoxo Intermediate of Cytochrome P450 2B4 Is Slower in the Presence of Cytochrome P450 Reductase Than in the Presence of Cytochrome b5. Biochemistry 2016, 55, 6558-6567. [CrossRef] [PubMed]

17. Hamdane, D.; Xia, C.; Im, S.-C.; Zhang, H.; Kim, J.-J.P.; Waskell, L. Structure and function of an NADPH-cytochrome P450 oxidoreductase in an open conformation capable of reducing cytochrome P450. J. Biol. Chem. 2009, 284, 11374-11384. [CrossRef] [PubMed]

18. Bridges, A.; Gruenke, L.; Chang, Y.T.; Vakser, I.A.; Loew, G.; Waskell, L. Identification of the binding site on cytochrome P450 2B4 for cytochrome b5 and cytochrome P450 reductase. J. Biol. Chem. 1998, 273, 17036-17049. [CrossRef] [PubMed]

19. Nash, T. The colorimetric estimation of formaldehyde by means of the Hantzsch reaction. Biochem. J. 1953, 55, 416-421. [CrossRef] [PubMed]

20. Saribas, A.S.; Gruenke, L.; Waskell, L. Overexpression and Purification of the Membrane-Bound Cytochrome P450 2B4. Protein Expr. Purif. 2001, 21, 303-309. [CrossRef] [PubMed] 